\title{
SIMULAÇÃO ECONÔMICA DE UMA UNIDADE PRODUTORA DE GRÃOS E COMPARAÇÃO DE CUSTOS PELO SISTEMA BARTER
}

Luiz Antonio Lorenzon*

Flávio Carlos Dalchiavon**

RESUMO: Objetivou-se oferecer ao produtor rural uma ferramenta de gerenciamento de custos e receitas da produção agrícola, pelo sistema Barter e aquisição à vista, para a safra 2016/17 em uma propriedade agrícola de Diamantino (MT), que cultiva soja e milho. Utilizou-se adaptação das metodologias da EMBRAPA, CONAB, IMEA e PECEGE/ESALQ. As produtividades e preços de venda utilizados foram, respectivamente, de 53 e 62,00 (soja) e 90 sc ha $^{-1}$ e $R \$ 22,00$ por saca (milho). Na modalidade a vista, a soja apresentou, por saca, um CVt de $\mathrm{R} \$ 44,54$, CFt de $\mathrm{R} \$ 15,18$ e CT de $\mathrm{R} \$$ 59,72, enquanto o milho possuiu um CVt de $\mathrm{R} \$ 18,18$, CFt $\mathrm{R} \$ 0,00$ e CT de $\mathrm{R} \$ 18,18$, conferindo lucro anual de $\mathrm{R} \$ 234.176,00$, com margem de lucro de 6,84\%. O sistema Barter apresentou, por saca, CVt de R $\$ 44,13$, CFt de R\$15,18 e CT de R \$ 59,32 para a soja e CVt de $\mathrm{R} \$ 17,96$, CFt de $\mathrm{R} \$ 0,00$ e CT de $\mathrm{R} \$ 17,96$ para o milho, com lucro anual de $\mathrm{R} \$ 323.256,00$ e margem de lucro de 9,28\%. Assim, barter mostra-se mais vantajoso até o preço de comercialização de $\mathrm{R} \$ 66,00$ e $\mathrm{R} \$ 22,50$ por saca, respectivamente, para soja e milho.

PALAVRAS-CHAVE: Agronegócio; Estrutura de custo; Glycine max; Indicadores financeiros; Zea mays.

\section{ECONOMIC SIMULATION OF A GRAIN-PRODUCING UNIT AND COMPARISON OF COSTS BY THE BARTER SYSTEM}

ABSTRACT: A tool for the management of costs and income in agricultural production is provided by means of the barter system and acquisition cash for the 201617 harvest on a farm in Diamantino MT Brazil, with soybean and corn. EMBRAPA, CONAB, IMEA and PECEGE/ESALQ methodologies were employed. Productivity and selling prices used were 53 sacks ha- 1 and $\mathrm{R} \$ 62.00$ (soybean) and 90 sacks ha- 1 and $\mathrm{R} \$ 22.00$ per sack (corn), respectively. Soybean per sack in cash mode provided CVt

\footnotetext{
Especialização em Agronegócio (MBA) pela Escola Superior de Agricultura "Luiz de Queiroz (ESALQ), Piracicaba, SP, Brasil.

** Doutor em Agronomia (Sistemas de Produção) pela Universidade Estadual Paulista "Julio de Mesquita FIlho", Faculdade de Engenharia de Ilha Solteira (UNESP/FEIS). Instituto Federal de Educação, Ciência e Tecnologia de Mato Grosso, Campus Campo Novo do Parecis Brasil. E-mail: flavio.dalchiavon@cnp.ifmt.edu.br
} 
at $\mathrm{R} \$ 44.54$, CFt at $\mathrm{R} \$ 15.18$ and $\mathrm{CT}$ at $\mathrm{R} \$ 59.72$, whereas corn provided $\mathrm{CVt}$ at $\mathrm{R} \$$ $18.18, \mathrm{CFt}$ at $\mathrm{R} \$ 0.00$ and $\mathrm{CT}$ at $\mathrm{R} \$ 18.18$, with an annual profit of $\mathrm{R} \$ 234,176.00$, at a $6.84 \%$ profit. The Barter system provided per sack CVt at $\mathrm{R} \$ 44.13$, CFt at $\mathrm{R} \$$ 15.18 and $\mathrm{CT}$ at $\mathrm{R} \$ 59.32$ for soybean, and CVt at $\mathrm{R} \$ 17.96, \mathrm{CFt}$ at $\mathrm{R} \$ 0.00$ and CT at $R \$ 17.96$ for corn, with an annual profit of $R \$ 323,256.00$ and a $9.28 \%$ profit. The Barter system proved to be more advantageous up to the commercialization price of $\mathrm{R} \$ 66.00$ and $\mathrm{R} \$ 22.50$ per sack, respectively, for soybean and corn.

KEY WORDS: Agribusiness; Cost structure; Glycine max; Financial indicators; Zea mays.

\section{INTRODUÇÃO}

O Estado de Mato Grosso é o maior produtor de grãos do Brasil, sendo o primeiro em soja, milho, milho pipoca, girassol e algodão, respondendo por aproximadamente $25 \%$ da produção nacional, conforme dados da Companhia Nacional de Abastecimento (CONAB, 2017), produzindo tanto para o mercado interno quanto para a exportação. Por estar longe dos mercados consumidores e portos exportadores, ganhos em escala e produtividade são fundamentais para permanecer competitivo, segundo o Instituto Mato-grossense de Economia Agrícola (IMEA, 2016).

A produção de grãos tem passado por inúmeros entraves, permanecendo na atividade os agricultores mais competitivos. A competitividade é influenciada pela disponibilidade de terras aptas à produção de grãos, condições climáticas, tecnologias, distância entre o local da produção e o seu destino final, políticas públicas macro e microeconômicas, bem como pela capacidade de trabalho e adaptabilidade dos produtores aos novos desafios (APROSOJA, 2016; DELAI et al., 2017). Neste caso, fala-se da competitividade da produção de grãos em si, ou seja, "porteira adentro", mas sem esquecer que em tempos de globalização, para permanecer na atividade, o agricultor precisa produzir com qualidade e com boa aceitação do produto pelo consumidor, colocando-o no ponto de consumo ao menor custo possível.

A produção agrícola, por ser uma atividade a "céu aberto", envolve inúmeros riscos, independentemente do tipo de produto que se quer colher ou da tecnologia empregada. Estes riscos existem em todas as etapas da produção, desde 
os processos que definem o que, onde, quando, quanto e a que preço produzir, tornando-se complexos os processos de decisões (MARTINES FILHO, 2007).

A determinação dos custos de produção agrícola geram informações contábeis que indicam a melhor forma de administrar e planejar as atividades, tanto na área de produção como no gerenciamento financeiro (MIRANDA, 2013). O levantamento de custos auxilia o produtor rural na gestão da atividade, possibilitando a análise dos componentes que envolvem a sua produção, o custo/benefício, tomada de decisão e identifica, juntamente com as informações do mercado, os riscos e as oportunidades ao longo dos anos (BROCH; PEDROSO, 2012).

Portanto, o custo de produção é uma ferramenta excepcional de controle e gerenciamento da sua atividade, indicando informações que subsidiem nas tomadas de decisões para que o produtor administre com eficiência e eficácia a sua propriedade (CONAB, 2010).

A lucratividade é avaliada através da análise dos preços e custos de produção. Os preços domésticos são influenciados pelas variações que ocorrem no mercado internacional, pois os agricultores não são formadores de preços, mas sim tomadores de preços no mercado externo (VALERINI; KUWAHARA, 2007).

Para auxiliar a tomada de decisão, no caso específico da produção de grãos em uma propriedade rural localizada no Centro-Oeste mato-grossense, é necessário ter em mãos uma ferramenta de coleta e análise de dados que seja eficiente, rápida e o mais simples possível, identificando, com as informações do mercado, os riscos e as oportunidades ao longo do processo produtivo e que possam responder as seguintes perguntas: "A propriedade é sustentável economicamente?", "Qual o custo médio, variável e fixo por unidade produzida?", "Na atual situação, o sistema de troca (Barter) é vantajoso?".

Para a escolha da propriedade do estudo, levou-se em consideração que a mesma pertence ao autor, da necessidade de dados fidedignos para o estudo, da dúvida dos produtores por ocasião da contratação, qual sistema é mais vantajoso - a vista ou o Barter e da rapidez do indicativo, propiciando ao produtor aproveitar as oportunidades ao longo do processo produtivo.

Barter, ou troca, é uma das alternativas amplamente utilizadas no mercado agrícola, devido à baixa complexidade do ponto de vista da operação, e que consiste 
na venda antecipada de parte da produção para a aquisição de insumos. É uma estratégia muito importante para o agricultor, que se protege da volatilidade, e interessante para os fornecedores de insumos, pois mitiga o risco de crédito (ROS, 2015).

$\mathrm{O}$ produtor geralmente inicia o seu planejamento anual de acordo com a área a ser plantada. A partir desta informação, poderá estimar o volume e os tipos de insumos necessários. As condições oferecidas de cada pacote (barter) podem variar de acordo com a escala dos produtores, ou seja, o tamanho da área cultivada (ARAKAWA, 2014).

O Índice de Confiança do Agronegócio (IC Agro), em sondagem de mercado do produtor agrícola no segundo trimestre de 2016, indicou que o aumento nos custos de produção e as dificuldades de obtenção de crédito pesaram na forma em que os produtores rurais bancaram a safra. A participação dos fornecedores que vendem a prazo, fora do sistema financeiro, e que negociam mais frequentemente os insumos em operações de troca da produção foi maior que o esperado inicialmente (ICAGRO, 2016).

As incertezas do cenário econômico brasileiro, aliadas às dificuldades na liberação de crédito nas instituições financeiras, têm levado os produtores rurais a buscarem alternativas para o financiamento da safra. Estão ganhando espaço e se popularizando as operações de Barter, evitando os altos juros e a burocracia dos bancos e instituições financeiras, ao mesmo tempo em que são vistas pelos fornecedores como uma forma de fidelizar clientes (PACHECO, 2016).

A fim de manter em equilíbrio os custos e receitas da produção, o agricultor precisa trabalhar e agir como um empresário, isto é, conhecer e controlar os fatores do processo (MARION et al., 1996). Embora se saiba que nem todos os fatores de produção estão sob o controle do produtor, este estudo atém-se aos fatores intrínsecos, "porteira adentro".

Ainda, para que a propriedade rural seja sustentável economicamente, o resultado econômico de suas atividades deve ser suficiente para remunerar os financiadores e garantir a manutenção dos recursos naturais para as gerações futuras, visto que o conceito de sustentabilidade econômica refere-se ao desenvolvimento econômico visando à preservação do meio ambiente e justiça social (PINHEIRO; BASSOLI, 2005). 
Objetivou-se oferecer ao produtor rural uma ferramenta de gerenciamento de custos e receitas da produção agrícola, que o ajude a responder os questionamentos propostos, utilizando o sistema Barter e aquisição à vista.

\section{MATERIAL E MÉTODOS}

\section{1 ÁREA DE ESTUDO}

O estudo refere-se aos dados reais de uma propriedade agrícola situada no município de Diamantino, Estado do Mato Grosso, dedicada à produção de grãos, sendo soja na safra de verão e milho na safra de inverno. A área total da propriedade é de 1.630 hectares, sendo 800 hectares de lavoura, 800 hectares de reserva legal e áreas de preservação permanentes e 30 hectares de benfeitorias (sede, estradas, pastagens, pomar etc.).

No verão, a soja ocupa $100 \%$ da área de lavoura. No inverno, o milho representa entre 40 e $60 \%$ desta área. No restante, em uma parte é realizada a correção da acidez do solo, enquanto a outra é coberta com milheto e/ou crotalária (culturas de cobertura).

A propriedade possui todos os maquinários necessários para a implantação, condução e colheita das culturas, sendo o custo de colheita computado em óleo diesel, peças, lubrificantes e filtros, bem como o custo de distribuição e incorporação de calcário. O custo de manutenção refere-se às despesas de mecânico e eletricistas, os quais são acionados quando os funcionários e o proprietário não conseguem resolver o problema. A assistência técnica está diluída na administração, pois o assistente técnico é o proprietário. O frete corresponde ao custo do transporte da produção até os armazéns, distantes 45 quilômetros da propriedade. A propriedade não faz seguro de máquinas, implementos e benfeitorias. 


\subsection{CUSTO DE PRODUÇÃO DA SOJA E DO MILHO}

A metodologia utilizada para apuração dos custos de produção é uma adaptação das metodologias utilizadas pela EMBRAPA (2014), CONAB (2010; 2016a), IMEA (2016) e PECEGE/ESALQ (2015), referentes ao ano de 2016, em relação à formação do custo total. Contudo, a planilha elaborada é mais simples, rápida e de fácil compreensão, podendo ser alimentada diariamente, fornecendo instantaneamente os indicadores mais importantes para a tomada de decisão, conforme informações do mercado.

Os componentes econômicos dos custos de produção são agrupados em:

a) Custos variáveis (CV), compostos pelo custo de formação e manejo das plantas de cobertura, pelos insumos (Barter) e pelos dispêndios com semeadura, tratos culturais, peças, combustível, mão de obra sazonal, colheita, frete, impostos de comercialização e seguro rural sem a subvenção. Os CVs, somados aos juros sobre o capital de giro (CG), formam o custo variável total (CVt).

b) Custos fixos (CF), constituídos pelos custos fixos desembolsáveis (CFd) (correção do solo, mão de obra fixa, administração e arrendamento (custo de oportunidade)) e pelos custos do capital não circulante (Kñ), que são as depreciações. O arrendamento (custo de oportunidade) considerou-se como pagamento antecipado, ou seja, antes do plantio da soja.

c) Custo total (CT) é a soma dos CVt e dos CF.

Os valores, em reais (R\$), têm por base o ano de 2016, sendo o custo de produção da soja referente à safra 2016/17, e do milho a safra 2017, ambos transgênicos e semeados no sistema de plantio direto, onde a palha e restos vegetais são deixados na superfície do solo (FERREIRA et al., 2015). Os preços dos insumos foram cotados em junho para pagamento em julho/2016 para a cultura da soja e outubro para pagamento em dezembro para a cultura do milho. Os valores das máquinas, veículos, implementos e benfeitorias, consideraram-se o preço de mercado do ano de 2016 e vida útil média de mais 10 anos. 
Para o cálculo da depreciação, considerou-se o valor inicial menos o valor residual dividido pela vida útil (Tabela 1 ). Para o cálculo do custo da terra, considerou-se o valor médio de arrendamento de 8 sacas de soja ha ${ }^{-1}$ ano $^{-1}$.

Tabela 1. Investimentos e custos em Kñ (2016)

\begin{tabular}{|l|c|c|c|}
\hline Investimento & Valor inicial $(\mathrm{R} \$)$ & Residual $(\%)$ & Valor residual (R\$) \\
\hline Máquinas & $850.000,00$ & 30,00 & $255.000,00$ \\
\hline Implementos & $320.000,00$ & 30,00 & $96.000,00$ \\
\hline Benfeitorias & $200.000,00$ & 60,00 & $120.000,00$ \\
\hline Valor da terra & 0,00 & 0,00 & 0,00 \\
\hline Total & $1.370 .000,00$ & & $471.000,00$ \\
\hline Custos & Total $(\mathrm{R} \$)$ & Soja $(\mathrm{R} \$)$ & Milho (R\$) \\
\hline Depreciação de Máquinas & $59.500,00$ & $59.500,00$ & 0,00 \\
\hline Depreciação de Implementos & $22.400,00$ & $22.400,00$ & 0,00 \\
\hline Depreciação de Benfeitorias & $8.000,00$ & $8.000,00$ & 0,00 \\
\hline Custo da Terra & 0,00 & 0,00 & 0,00 \\
\hline Total da Depreciação & $89.900,00$ & $89.900,00$ & 0,00 \\
\hline Juros do Capital Investido & 0,00 & 0,00 & 0,00 \\
\hline PGTO Custo do Capital & $89.900,00$ & $89.900,00$ & 0,00 \\
\hline
\end{tabular}

Fonte: Elaborado pelo autor com base nas planilhas do PECEGE/ESALQ (2015).

Para o cálculo dos juros sobre o CG, considerou-se taxa de 8,75\% a. a., com prazo médio de nove meses. Para Kñ, desconsideraram-se os juros (PECEGE/ESALQ, 2015).

O CG é formado pela soma do CV e do CFd. Para o cálculo do prêmio do seguro rural da cultura da soja, considerou-se uma cobertura de $65 \%$ da receita esperada a uma taxa de $4,34 \%$. Para a cultura do milho, para uma cobertura de $60 \%$ do (CV), excluído o prêmio, considerou-se uma taxa de 6,75\% (Tabela 2). O seguro rural é uma forma de se precaver contra as perdas financeiras decorrentes das adversidades climáticas (MAPA, 2017). 
Tabela 2. Seguro Rural/Cálculo do Prêmio (2016)

\begin{tabular}{lcccc}
\hline & \multicolumn{2}{c}{ Soja } & \multicolumn{2}{c}{ Milho } \\
\cline { 2 - 5 } Agrícola (\%) & Faturamento (\%) & Nível cobertura (\%) & Nível de cobertura (\%) & Taxa (\%) \\
\hline 3,90 & 4,90 & 80,00 & 60,00 & 6,75 \\
3,61 & 4,77 & 75,00 & 65,00 & 7,75 \\
3,52 & 4,54 & 70,00 & - & - \\
3,34 & 4,34 & 65,00 & - & - \\
0,00 & 4,34 & 65 & 60 & 6,75 \\
\hline
\end{tabular}

Fonte: Elaborado pelo autor com informações do Banco do Brasil (2016).

Para o cálculo do Fethab/Facs, considerou-se o Informe Técnico no 143/2017, da Associação dos Produtores de Soja e Milho do Mato Grosso (APROSOJA, 2017), e a Portaria 224/2016, da Secretaria de Estado de Fazenda do Mato Grosso (SEFAZ/ MT, 2016). Para o Funrural, considerou-se uma alíquota de 2,3\% sobre a receita total (RT). Os valores referência para o Fethab Soja (Fundo Especial de Transporte e Habitação), Fethab Regional e para o Facs (Fundo de Apoio à Cultura da Soja) para janeiro de 2017 foram, respectivamente, de $\mathrm{R} \$ 9,605$, $\mathrm{R} \$ 9,605$ e $\mathrm{R} \$ 1,260$, com base na Unidade Padrão Fiscal (UPF/MT $=\mathrm{R} \$ 128,66)$, totalizando $\mathrm{R} \$ 20,47$. Tais valores equivalem a $\mathrm{R} \$ 26,34$ por tonelada ( $\mathrm{R} \$ 12,36$ Fethab Soja $+\mathrm{R} \$ 12,36$ Fethab Regional $+\mathrm{R} \$ 1,62$ Facs) ou $\mathrm{R} \$ 1,58$ por saca de produto $(\mathrm{R} \$ 0,74$ Fethab Soja $+\mathrm{R} \$ 0,74$ Fethab Regional + R\$0,10 Facs).

\subsection{ANÁLISE ECONÔMICA}

\subsubsection{Sistema de Custos Normal}

Para a análise econômica do sistema de custos normal, avaliou-se a produtividade média das últimas três safras e o preço médio dos produtos almejados (soja e milho) por ocasião da colheita, formando a receita. Para o CG total, considerou-se o CV mais o CFd ou circulante. O CF do capital não circulante (Kñ), que somado ao CFd ou circulante, forma o CFt. O CT é a soma do CV e dos juros sobre o CG (CVt), mais o CFt. O Custo Operacional Efetivo (COE), considerando-se o arrendamento, é a soma do CVt e do CFd. A Receita Média Ponderada, o CT ponderado e o LT ponde- 
rado são, respectivamente, a receita da área total da soja mais a receita da área total do milho dividido pela área disponível; o CT da área total da soja mais o CT da área total do milho dividido pela área disponível e o lucro total anual dividido pela área disponível. Ou seja, a ponderação é o produto da área de soja somado ao produto da área de milho e dividido pela área disponível.

A Margem de Contribuição bruta (MCb) é a receita apurada, descontado o CVt, enquanto que a Margem de Contribuição Operacional efetiva (MCOe) é a MCb da soja e do milho subtraído do CFd circulante (lucro total anual mais as depreciações, considerando o custo de oportunidade). O Ponto de Equilíbrio (PE) é o CFt dividido pela MCb. A MCOe sem o arrendamento é a soma da MCOe mais o arrendamento (custo de oportunidade), também conhecido como lucro financeiro (EMBRAPA, 2014). O lucro antes da retirada dos juros e depreciações (EBITDA) é o somatório das Margens Operacionais Efetivas (MOe) e dos juros sobre o CG. O lucro (L) é o saldo das receitas subtraído o custo total, e a margem de lucro é o percentual do lucro em relação às receitas. No CFt da safra de verão ponderou-se apenas a área e produção da safra de soja, enquanto que o diluído levou em conta ambas as safras.

\subsubsection{Sistema de Custos (Barter)}

Para a análise econômica no sistema Barter considerou-se a produtividade média das últimas três safras e o preço médio dos produtos almejados por ocasião da colheita para a produção livre. A receita total (RT) é a receita livre mais o custo do Barter. O CG é a soma do CV sem os insumos mais o CFd. No CVt, os insumos representam o custo do Barter. O CF é a soma do CFd mais o CF do Kñ circulante, e o CT é a soma do CVt mais o CFt. O lucro é o saldo das receitas subtraído o custo médio ao passo que a margem de lucro é o percentual do lucro em relação às receitas.

Também se considerou o CFt apenas na safra de soja (usual) e diluído em ambas as safras (soja e milho). 


\section{RESULTADOS E DISCUSSÃO}

\subsection{SISTEMA DE CUSTOS NORMAL}

O custo total de produção para a cultura da soja na safra 2016/17 na referida propriedade foi de $R \$ 2.532 .335,32$, compostos de $R \$ 1.732 .963,82$ de custo variável, $\mathrm{R} \$ 150.413,91$ de juros sobre o capital de giro e $\mathrm{R} \$ 643.700,00$ de custo fixo, representando por hectare, respectivamente, $\mathrm{R} \$ 3.165,42$ de CT, R\$2.172,78 de CV, $\mathrm{R} \$ 188,02$ de juros sobre o CG e $\mathrm{R} \$ \mathbf{8 0 4 , 6 3}$ de CFt (Tabela 3). O frete representou $2,49 \%$ do custo total de produção, representando o significativo montante de $\$$ \$ 63.000,00. Souza, Cremasco e Gabriel Filho (2016) já haviam se referido a esse importante, e impactante, item no custo total da produção, ao salientarem que o transporte rodoviário é mais utilizado no país, no entanto, entre as suas limitações pode-se destacar o elevado custo de frete, quando comparado com as modalidades ferroviária e hidroviária. Desta forma, os custos de escoamento das safras têm sido um entrave para o Brasil transformar vantagens comparativas da produção em competitividade na comercialização (OLIVEIRA et al., 2015).

Tabela 3. Custo de produção da soja safra 2016/17

\begin{tabular}{|c|c|c|c|}
\hline Insumos & Total (R\$; 800 ha $)$ & $\mathbf{R} \$ \mathbf{h a}^{-1}$ & $\%$ do insumo* \\
\hline Sementes & $205.000,00$ & 256,25 & 8,10 \\
\hline Tratamento de sementes & $16.000,00$ & 20,00 & 0,63 \\
\hline Inoculantes & $4.000,00$ & 5,00 & 0,16 \\
\hline Adubo/semeadura & $345.000,00$ & 431,25 & 13,62 \\
\hline Adubo/cobertura & $180.000,00$ & 225,00 & 7,11 \\
\hline Micronutrientes & $32.000,00$ & 40,00 & 1,26 \\
\hline Inseticidas & $195.000,00$ & 243,75 & 7,70 \\
\hline Herbicidas & $140.000,00$ & 175,00 & 5,53 \\
\hline Fungicidas & $175.000,00$ & 218,75 & 6,91 \\
\hline Adjuvantes & $29.600,00$ & 37,00 & 1,17 \\
\hline A1 - Total insumos Barter (R\$) & $1.321 .600,00$ & $1.652,00$ & 52,19 \\
\hline Plantas de cobertura & $10.000,00$ & 12,50 & 0,39 \\
\hline Manejo da cobertura & $8.000,00$ & 10,00 & 0,32 \\
\hline Óleo diesel & $65.000,00$ & 81,25 & 2,57 \\
\hline
\end{tabular}




\begin{tabular}{|c|c|c|c|}
\hline Lubrificantes/graxas & $9.000,00$ & 11,25 & 0,36 \\
\hline Filtro/peças & $16.000,00$ & 20,00 & 0,63 \\
\hline Manutenção & $5.000,00$ & 6,25 & 0,20 \\
\hline Despesas cantina & $15.000,00$ & 18,75 & 0,59 \\
\hline Mão de obra sazonal & $24.000,00$ & 30,00 & 0,95 \\
\hline Assistência técnica & 0,00 & 0,00 & 0,00 \\
\hline Colheita & 0,00 & 0,00 & 0,00 \\
\hline Frete & $63.000,00$ & 78,75 & 2,49 \\
\hline Armazenagem & 0,00 & 0,00 & 0,00 \\
\hline Fethab/facs ** & $67.000,57$ & 83,75 & 2,65 \\
\hline Funrural *** & $60.462,40$ & 75,58 & 2,39 \\
\hline Seguro Rural & $74.158,45$ & 92,70 & 2,93 \\
\hline A2 - Sub total Variável & $416.621,42$ & 520,77 & 16,45 \\
\hline A - Total Variável (CF) $(\mathrm{R} \$)(\mathrm{A} 1+\mathrm{A} 2)$ & $1.738 .221,42$ & $2.172,78$ & 68,64 \\
\hline Calcário posto na fazenda & $45.000,00$ & 56,25 & 1,78 \\
\hline Distribuição/incorporação calcário & 0,00 & 0,00 & 0,00 \\
\hline Despesas/fone/energia elétrica & $12.000,00$ & 15,00 & 0,47 \\
\hline Mão de obra fixa & $60.000,00$ & 75,00 & 2,37 \\
\hline Administração & $40.000,00$ & 50,00 & 1,58 \\
\hline Arrendamento (custo de oportunidade) & $396.800,00$ & 496,00 & 15,67 \\
\hline B1 - Custo Fixo Desembolsável (CFd) & $553.800,00$ & 692,25 & 21,87 \\
\hline Depreciação/máquinas/implementos & $81.900,00$ & 102,38 & 3,23 \\
\hline Depreciação/benfeitorias & $8.000,00$ & 10,00 & 0,32 \\
\hline Seguro de máquinas/benfeitorias & 0,00 & 0,00 & 0,00 \\
\hline Custo da terra & 0,00 & 0,00 & 0,00 \\
\hline Juros sobre Kñ circulante & 0,00 & 0,00 & 0,00 \\
\hline B2 - Custo Fixo Kñ circulante (CF Kñ) & $89.900,00$ & 112,38 & 3,55 \\
\hline B - Total Fixo (CFt) $(\mathrm{B} 1+\mathrm{B} 2)(\mathrm{R} \$)$ & $643.700,00$ & 804,63 & 25,42 \\
\hline Total $(\mathrm{A}+\mathrm{B})(\mathrm{R} \$)$ & $2.381 .921,42$ & 2.977 .40 & 94,06 \\
\hline Juros sobre CG $(\mathrm{C})(\mathrm{R} \$)$ & $150.413,91$ & 188,02 & 5,94 \\
\hline Custo Totalcom juros CG $(\mathrm{A}+\mathrm{B}+\mathrm{C})(\mathrm{R} \$)$ & $2.532 .335,32$ & $3.165,42$ & 100,00 \\
\hline
\end{tabular}

Fonte: Elaborado pelo autor com base nas planilhas da EMBRAPA (2014), CONAB (2010), IMEA-MT (2016) e PECEGE/ESALQ (2015). * \% do insumo em relação ao custo total; ** Fundo Especial de Transporte e Habitação/Fundo de Apoio à Cultura da Soja; *** Fundo de Assistência ao Trabalhador Rural. 
Estes custos representam por unidade produzida respectivamente, $\mathrm{R} \$ 59,72$ de CT, $R \$ 44,54$ de CVt e $R \$ 15,18$ de CFt, resultando em um lucro de $\mathrm{R} \$ 120,58$ por hectare semeado, apresentando PE de 695,74 ha-1 ou 46,09 scha-1 (Tabela 4). A obtenção dos custos unitários é muito importante, pois permite ao agricultor (empresário) empregar os dados contábeis e financeiros para estabelecer os custos de produção objetivando alcançar uma operação racional, eficiente e lucrativa, uma vez que o controle dos gastos e sua contínua redução é vital para a sobrevivência do agricultor, de forma que os que não se reorganizarem/adaptarem a este novo ambiente competitivo, não sobreviverão (BORGES; MAINARDI; VELASQUEZ, 2003).

Tabela 4. Análise Econômica Sistema Normal (custo e lucro do ano agrícola) 2016/17

\begin{tabular}{|c|c|c|}
\hline Especificações & Soja & Milho \\
\hline Área em hectares & 800,00 & 400,00 \\
\hline Produtividade scha ${ }^{-1}$ & 53,00 & 90,00 \\
\hline Produção (sc) & $42.400,00$ & $36.000,00$ \\
\hline Preço $\left(\mathrm{R} \$ \mathrm{sc}^{-1}\right)$ & 62,00 & 22,00 \\
\hline Receita Média $\left(\mathrm{R} \$ \mathrm{ha}^{-1}\right)$ & $3.286,00$ & $1.980,00$ \\
\hline Receita Média Ponderada $\left(\mathbf{R} \$ h^{-1}\right)$ & \multicolumn{2}{|c|}{$4.276,00$} \\
\hline Receita Total (R\$) & $2.628 .800,00$ & $792.000,00$ \\
\hline CV (R\$) & $2.172,78$ & $1.535,11$ \\
\hline $\mathrm{CG}(\mathrm{R} \$)$ & $2.292 .021,42$ & $614.043,08$ \\
\hline Juros sobre CG (R\$) & $150.413,91$ & $40.296,58$ \\
\hline CVt Total $(\mathrm{R} \$)$ & $1.888 .635,32$ & $654.339,66$ \\
\hline $\mathrm{CFd}(\mathrm{R} \$)$ & $553.800,00$ & 0,00 \\
\hline CF Kñ (R\$) & $89.900,00$ & 0,00 \\
\hline $\mathrm{COE}(\mathrm{R} \$)$ & $2.442 .435,32$ & $654.339,66$ \\
\hline $\mathrm{CFt}\left(\mathrm{R} \$ \mathrm{ha}^{-1}\right)$ & 804,63 & 0,00 \\
\hline $\mathrm{CT}\left(\mathrm{R} \$ \mathrm{ha}^{-1}\right)$ & $3.165,42$ & $1.635,85$ \\
\hline CT Ponderado $\left(\mathbf{R} \$ h^{-1}\right)$ & \multicolumn{2}{|c|}{$3.983,34$} \\
\hline $\mathrm{CT}\left(\mathrm{R} \$ \mathrm{sc}^{-1}\right)$ & 59,72 & 18,18 \\
\hline LT $\left(\mathrm{R} \$ \mathrm{ha}^{-1}\right)$ & 120,58 & 344,15 \\
\hline LT Ponderado $\left(\mathbf{R} \$ \mathrm{ha}^{-1}\right)$ & \multicolumn{2}{|c|}{292,66} \\
\hline CFt (safra de verão/soja) $\left(\mathrm{R} \$ \mathrm{sc}^{-1}\right)$ & 15,18 & - \\
\hline $\mathrm{CVt}\left(\mathrm{R} \$ \mathrm{sc}^{-1}\right)$ & 44,54 & 18,18 \\
\hline
\end{tabular}




\begin{tabular}{|c|c|c|}
\hline Especificações & Soja & Milho \\
\hline CFt diluído safra de milho $\left(\mathrm{R} \$ \mathrm{sc}^{-1}\right)$ & 10,12 & 5,96 \\
\hline CT com CFt diluído safra de milho ( $\mathrm{R} \$ \mathrm{sc}^{-1}$ ) & 54,66 & 24,14 \\
\hline $\mathrm{CVt}\left(\mathrm{R} \$ \mathrm{ha}^{-1}\right)$ & $2.360,79$ & $1.635,85$ \\
\hline $\mathrm{MCb}\left(\mathrm{R} \$ \mathrm{ha}^{-1}\right)$ & 925,21 & 344,15 \\
\hline $\mathrm{MCb}(\mathrm{R} \$)$ & $740.164,68$ & $137.660,34$ \\
\hline IMC (\%) & 28,16 & 17,38 \\
\hline IMC Ponderado (\%) & \multicolumn{2}{|c|}{25,66} \\
\hline MCOe $(\mathrm{R} \$)$ & \multicolumn{2}{|c|}{$324.025,02$} \\
\hline MCOe Sem arrendamento (CO) (R\$) & \multicolumn{2}{|c|}{$720.825,02$} \\
\hline EBITDA (R\$) & \multicolumn{2}{|c|}{$514.735,50$} \\
\hline Lucro Total Anual (R\$) & \multicolumn{2}{|c|}{$234.125,02$} \\
\hline $\mathrm{RT}(\mathrm{R} \$)$ & \multicolumn{2}{|c|}{$3.420 .800,00$} \\
\hline Receita de Equilíbrio (RE) (R\$) & \multicolumn{2}{|c|}{$2.508 .437,23$} \\
\hline Margem de Lucro (ML) (\%) & \multicolumn{2}{|c|}{6,84} \\
\hline Ponto de Equilíbrio (PE) em há & \multicolumn{2}{|c|}{695,74} \\
\hline MC Ponderada (R\$) & \multicolumn{2}{|c|}{$1.097,28$} \\
\hline CG total anual com juros $(\mathrm{R} \$)$ & \multicolumn{2}{|c|}{$3.096 .774,98$} \\
\hline Investimento total em $(\mathrm{R} \$)$ & \multicolumn{2}{|c|}{$4.466 .774,98$} \\
\hline
\end{tabular}

PE (sc ha-1 - Soja) 46,09

Fonte: Elaborado pelo autor com base nas planilhas da EMBRAPA (2014), CONAB (2010), IMEA-MT (2016) e PECEGE/ESALQ (2015).

Se diluir o CF total com a safra de milho, o CT por hectare ficaria em $\mathrm{R} \$$ 2.896,98. Por unidade produzida (saca), ter-se-ia um CT de $\mathbf{R} \$ 54,66$, CVt de R\$ 44,54 , um CFt de $\mathrm{R} \$ 10,12$, resultando em um lucro de $\mathrm{R} \$ 389,02$ por hectare semeado. $\mathrm{O}$ resultado do ano agrícola permanece inalterado como mostrado na Tabela 5. 
Tabela 5. Resultado dos Sistemas de Custos (Normal e Barter)

\begin{tabular}{|c|c|c|c|c|}
\hline \multirow{2}{*}{$\begin{array}{l}\text { Sistema de custo } \\
\text { Cultura }\end{array}$} & \multicolumn{2}{|c|}{ Normal } & \multicolumn{2}{|c|}{ Barter } \\
\hline & Soja & Milho & Soja & Milho \\
\hline $\mathrm{CVt}\left(\mathrm{R} \$ \mathrm{sc}^{-1}\right)$ & 44,54 & 18,18 & 44,13 & 17,96 \\
\hline CFt Safra verão $\left(\mathrm{R} \$ \mathrm{sc}^{-1}\right)$ & 15,18 & - & 15,18 & - \\
\hline $\mathrm{CT}\left(\mathrm{R} \$ \mathrm{sc}^{-1}\right)$ & 59,72 & 18,18 & 59,32 & 17,96 \\
\hline Lucro Médio $\left(\mathrm{R} \$ \mathrm{ha}^{-1}\right)$ & 120,58 & 344,15 & 222,49 & 363,70 \\
\hline Lucro Total Anual (R\$) & \multicolumn{2}{|c|}{$234.125,02$} & \multicolumn{2}{|c|}{$323.475,33$} \\
\hline Margem de Lucro (\%) & \multicolumn{2}{|c|}{6,84} & \multicolumn{2}{|c|}{9,28} \\
\hline CFt diluído $\left(\mathrm{R} \$ \mathrm{sc}^{-1}\right)$ & 10,12 & 5,96 & 10,12 & 5,96 \\
\hline $\mathrm{CVt}\left(\mathrm{R} \$ \mathrm{sc}^{-1}\right)$ & 44,54 & 18,18 & 44,13 & 17,96 \\
\hline $\mathrm{CT}\left(\mathrm{R} \$ \mathrm{sc}^{-1}\right)$ & 54,66 & 24,14 & 54,26 & 23,92 \\
\hline Lucro Médio $\left(\mathrm{R} \$ \mathrm{ha}^{-1}\right)$ & 389,02 & $-192,60$ & 490.47 & $-172,80$ \\
\hline Lucro Total Anual (R\$) & \multicolumn{2}{|c|}{$234.176,00$} & \multicolumn{2}{|c|}{$323.256,00$} \\
\hline Margem de Lucro (\%) & \multicolumn{2}{|c|}{6,84} & \multicolumn{2}{|c|}{9,28} \\
\hline
\end{tabular}

Fonte: Resultados originais da pesquisa

Para a cultura do milho (Tabela 6), o custo total de produção (400 hectares)

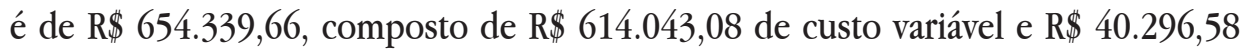
de juros sobre o capital de giro, representando, respectivamente, $R \$ 1.635,85$, $\mathrm{R} \$ 1.535,11$ e $\mathrm{R} \$ 100,74$ por hectare. O frete representou impacto financeiro ainda maior que na soja, com $6,88 \%$ do custo total de produção e montante de $R \$$ 45.000,00.

O alto custo logístico no Brasil, por vezes, impede a sustentabilidade das atividades produtivas, em especial as do setor do agronegócio, setor essencial para o desenvolvimento da economia nacional, caracterizado por produtos de grandes volumes e baixo valor agregado, como é o caso do milho (SILVA; MENEZES, 2008).

Tabela 6. Custo de produção do milho safra 2017 (Continua)

\begin{tabular}{lccc}
\hline Insumo & Total $(\mathrm{R} \$ ; 00 \mathrm{ha})$ & $\mathrm{R} \$ \mathrm{ha}^{-1}$ & $\%$ insumo* \\
\hline Sementes de milho & $120.000,00$ & 300,00 & 18,39 \\
Tratamento de sementes & 0,00 & 0,00 & 0,00 \\
Inoculantes & 0,00 & 0,00 & 0,00 \\
\hline
\end{tabular}


(Continua)

\begin{tabular}{|c|c|c|c|}
\hline Insumo & Total (R\$; 400 ha) & $\mathrm{R} \$ \mathrm{ha}^{-1}$ & $\%$ insumo* \\
\hline Adubo/semeadura & $102.000,00$ & 255,00 & 15,63 \\
\hline Adubo/cobertura & $105.000,00$ & 262,50 & 16,09 \\
\hline Micronutrientes & $8.500,00$ & 21,25 & 1,30 \\
\hline Inseticidas & $40.000,00$ & 100,00 & 6,13 \\
\hline Herbicidas & $45.000,00$ & 112,50 & 6,90 \\
\hline Fungicidas & 0,00 & 0,00 & 0,00 \\
\hline Adjuvantes & $8.000,00$ & 20,00 & 1,23 \\
\hline A1 - Total insumos Barter & $428.500,00$ & $1.071,25$ & 65,67 \\
\hline Plantas de Cobertura & 0,00 & 0,00 & 0,00 \\
\hline Óleo diesel & $20.000,00$ & 50,00 & 3,06 \\
\hline Lubrificantes/graxas & $4.500,00$ & 11,25 & 0,69 \\
\hline Filtro/peças & $6.000,00$ & 15,00 & 0,92 \\
\hline Manutenção & $3.000,00$ & 7,50 & 0,46 \\
\hline Despesas cantina & $6.000,00$ & 15,00 & 0,92 \\
\hline Mão de obra sazonal & $12.000,00$ & 30,00 & 1,83 \\
\hline Assistência técnica & 0,00 & 0,00 & 0,00 \\
\hline Colheita & 0,00 & 0,00 & 0,00 \\
\hline Frete & $45.000,00$ & 112,50 & 6,88 \\
\hline Armazenagem & $32.000,00$ & 80,00 & 4,89 \\
\hline Fethab/Facs *** & 0,00 & 0,00 & 0,00 \\
\hline Funrural & $18.322,92$ & 45,54 & 2,78 \\
\hline Seguro rural & $38.720,16$ & 96,80 & 5,93 \\
\hline A2 - Sub total variável & $185.543,08$ & 463,59 & 28,17 \\
\hline A - Total Variável (A1+A2) & $614.043,08$ & $1.535,11$ & 93,84 \\
\hline Calcário & 0,00 & 0,00 & 0,00 \\
\hline Distribuição/incorporação & 0,00 & 0,00 & 0,00 \\
\hline Despesas/fone/energia elétrica & 0,00 & 0,00 & 0,00 \\
\hline Mão de obra fixa & 0,00 & 0,00 & 0,00 \\
\hline Administração & 0,00 & 0,00 & 0,00 \\
\hline Arrendamento (custo de oportunidade) & 0,00 & 0,00 & 0,00 \\
\hline Depreciação/máquinas/implementos & 0,00 & 0,00 & 0,00 \\
\hline Seguro de máquinas/benfeitorias & 0,00 & 0,00 & 0,00 \\
\hline
\end{tabular}


(Conclusão)

\begin{tabular}{|c|c|c|c|}
\hline Insumo & Total (R\$; 400 ha) & $\mathrm{R} \$ \mathrm{ha}^{-1}$ & $\%$ insumo* \\
\hline Custo da terra & 0,00 & 0,00 & 0,00 \\
\hline Juros sobre o Kñ circulante & 0,00 & 0,00 & 0,00 \\
\hline B - Total Fixo (R\$) & 0,00 & 0,00 & 0,00 \\
\hline Total $(\mathrm{A}+\mathrm{B})(\mathrm{R} \$)$ & $614.043,08$ & $1.535,11$ & 93,84 \\
\hline Juros sobre $C G(\mathrm{C})(\mathrm{R} \$)$ & $40.296,58$ & 100,74 & 6,16 \\
\hline Custo Total $(\mathrm{CT})(\mathrm{A}+\mathrm{B}+\mathrm{C})(\mathrm{R} \$)$ & $654.339,66$ & $1.635,85$ & 100,00 \\
\hline
\end{tabular}

Fonte: Elaborado pelo autor com base nas planilhas da EMBRAPA (2014), CONAB (2010), IMEA-MT (2016) e PECEGE/ESALQ (2015). * \% do insumo em relação ao custo total; ** Fundo Especial de Transporte e Habitaçãp ${ }^{-1}$ Fundo de Apoio à Cultura da Soja; *** Fundo de Assistência ao Trabalhador Rural.

Por unidade produzida (sacas de milho), o CVt é de $\mathrm{R} \$ 18,18$. Como o CFt na propriedade analisada é considerado apenas na safra de verão, o CFt é zero e o CT é igual ao CVt. Sendo assim, a cultura do milho representa lucro de $\mathrm{R} \$ 344,15$ por hectare semeado (Tabela 5).

Ao diluir o custo fixo da safra de verão proporcional à área de inverno, ter-se-ia para a cultura do milho, por hectare, CVt de $\mathrm{R} \$ 1.635,85$, CFt de $\mathrm{R} \$ 536,40 \mathrm{e}$ CT de $\mathrm{R} \$ 2.172,60$, que por unidade produzida (saca) representaria um CVt de $\mathrm{R} \$$ 18,18 , CFt de $\mathrm{R} \$ 5,96$ e CT de $\mathrm{R} \$ 24,14$. Neste caso, a cultura do milho representaria um prejuízo de $\mathrm{R} \$ 192,60$ por hectare semeado, permanecendo inalterado o resultado anual.

O Instituto Mato-grossense de Economia Agropecuária (IMEA, 2016) estima para a cultura da soja transgênica, safra 2016/17, um CT de R $\$ 3.032,76$ por hectare, média para o Mato Grosso, variando de $\mathrm{R} \$ 2.631,08$, para a região Centro-Sul, a R\$3.409,05, para a região Nordeste do Estado. Em relação à cultura do milho alta tecnologia, estima-se um custo total médio para o Mato Grosso de $\mathrm{R} \$ 2.389,40$ por hectare, variando de $R \$ 2.138,11$, para a região Oeste, a $R \$ 2.611,50$, para a região Sudeste do Estado, enquanto que para o milho média tecnologia, que seria o caso da propriedade em análise, um CT de $\mathrm{R} \$ 2.063,40$ por hectare, sendo $\mathrm{R} \$ 1.946,03$ para a região Oeste e $R \$ 2.187,03$ para a região Nordeste.

Embora haja diferenças nos componentes dos custos de produção do IMEA com os componentes considerados pela propriedade e no caso do Instituto, os cus- 
tos fixos são considerados em ambas as culturas e não considera o custo do seguro rural. O resultado final, ou seja, o custo total da propriedade, está bem próximo do custo do IMEA.

A Companhia Nacional de Abastecimento (CONAB, 2016b; c) estima para o Mato Grosso, nas culturas de soja verão e milho segunda safra, um custo total (CT), respectivamente, de $\mathrm{R} \$ 2.828,27$ e $\mathrm{R} \$ 2.344,46$ por hectare. Aqui também considera-se o custo fixo em ambas as culturas e não se considera o custo do seguro rural. No caso do milho, a diferença entre a estimativa da CONAB e a utilizada pela propriedade é basicamente de tecnologia empregada.

\subsection{SISTEMA DE CUSTOS (BARTER)}

No sistema de trocas Barter, para a cultura da soja, foi verificado um CVt, por hectare, de $\mathrm{R} \$ 2.339,13$, CFt de $\mathrm{R} \$ 804,63$ e CT de $\mathrm{R} \$ 3.143,76$ (Tabela 7 ), representando por unidade produzida (saca), respectivamente, $\mathrm{R} \$ 44,13, \mathrm{R} \$ 15,18$ e $\mathrm{R} \$$ 59,32 , correspondendo a um lucro de $\mathrm{R} \$ 222,49$ por hectare semeado. Lucro, este $84,5 \%$ superior ao sistema normal em decorrência de um menor CVt e maior RT.

Tabela 7. Análise e Simulação com Barter (2016/17)

(Continua)

\begin{tabular}{|c|c|c|}
\hline Especificações & Soja & Milho \\
\hline Área em hectares & 800,00 & 400,00 \\
\hline Produtividade (sc ha ${ }^{-1}$ ) & 53,00 & 90,00 \\
\hline Produção (sc) & $42.400,00$ & $36.000,00$ \\
\hline Preço $\left(\mathrm{R}_{\$} \mathrm{sc}^{-1}\right)$ & 62,00 & 22,00 \\
\hline Receita Média $\left(\mathrm{R} \$ \mathrm{ha}^{-1}\right)$ & $3.366,25$ & $1.980,00$ \\
\hline Receita Média Ponderada $\left(\mathrm{R} \$ \mathrm{ha}^{-1}\right)$ & \multicolumn{2}{|c|}{$4.356,25$} \\
\hline Proporção da área total cultivada (\%) & 100,00 & 50,00 \\
\hline Preço da Troca $\left(\mathrm{R} \$ \mathrm{sc}^{-1}\right)$ (Barter) & 65,00 & 22,00 \\
\hline Quantidade $\left(\right.$ sc ha $\left.^{-1}\right)$ (Barter) & 26,75 & 51,00 \\
\hline Produção livre (sc ha' $\left.{ }^{-1}\right)$ & 26,25 & 39,00 \\
\hline Receita Média Livre $\left(\mathrm{R} \$ \mathrm{ha}^{-1}\right)$ & $1.627,50$ & 858,00 \\
\hline Insumos $\left(\mathrm{R} \mathrm{ha}^{-1}\right)$ (Barter) & $1.738,75$ & $1.122,00$ \\
\hline Óleo, Peças, etc (mecanização) $\left(\mathrm{R} \$ \mathrm{ha}^{-1}\right)$ & 137,50 & 98,75 \\
\hline
\end{tabular}


(Continua)

\begin{tabular}{|c|c|c|}
\hline Especificações & Soja & Milho \\
\hline MO mais cobertura e manejo $\left(\mathrm{R} \$ \mathrm{ha}^{-1}\right)$ & 52,50 & 30,00 \\
\hline Custo de colheita e pós colheita ( $\left(\mathrm{R} \$ \mathrm{ha}^{-1}\right)$ & 330,78 & 335,11 \\
\hline $\mathrm{CV}\left(\mathrm{R} \$ \mathrm{ha}^{-1}\right)$ & $2.259,53$ & $1.585,86$ \\
\hline $\mathrm{CG}(\mathrm{R} \$)$ & $970.421,42$ & $185.543,08$ \\
\hline Juros sobre CG (R\$) & $63.683,91$ & $12.176,26$ \\
\hline Juros sobre CG $\left(\mathrm{R} \$ \mathrm{ha}^{-1}\right)$ & 79,60 & 30,44 \\
\hline $\mathrm{CVt}\left(\mathrm{R} \$ \mathrm{ha} \mathrm{a}^{-1}\right)$ & $2.339,13$ & $1.616,30$ \\
\hline $\mathrm{RT}(\mathrm{R} \$)$ & $2.693 .000,00$ & $792.000,00$ \\
\hline CFd (R\$) & $553.800,00$ & 0,00 \\
\hline $\mathrm{COE}(\mathrm{R} \$)$ & $2.425 .104,00$ & $646.520,00$ \\
\hline CF Kñ (R\$) & $89.900,00$ & 0,00 \\
\hline CF Total (R\$) & \multicolumn{2}{|c|}{$643.700,00$} \\
\hline $\mathrm{CFt}\left(\mathrm{R} \$ \mathrm{ha}^{-1}\right)$ & 804,63 & 0,00 \\
\hline $\mathrm{CT}\left(\mathrm{R} \$ \mathrm{ha}^{-1}\right)$ & $3.143,76$ & $1.616,30$ \\
\hline CT Ponderado $\left(\mathrm{R} \$ \mathrm{ha}^{-1}\right)$ & \multicolumn{2}{|c|}{$3.951,91$} \\
\hline $\mathrm{CT}\left(\mathrm{R} \$ \mathrm{sc}^{-1}\right)$ & 59,32 & 17,96 \\
\hline Lme $\left(\mathrm{R} \$ \mathrm{ha}^{-1}\right)$ & 222,49 & 363,70 \\
\hline Lme Ponderado $\left(\mathrm{R} \$ \mathrm{ha}^{-1}\right)$ & \multicolumn{2}{|c|}{404,34} \\
\hline CFt (safra de verão/soja) $\left(\mathrm{R} \$\right.$ sc $\left.^{-1}\right)$ & 15,18 & - \\
\hline $\mathrm{CVt}\left(\mathrm{R} \$ \mathrm{sc}^{-1}\right)$ & 44,13 & 17,96 \\
\hline CFt diluído safra de milho $\left(\mathrm{R} \$ \mathrm{sc}^{-1}\right)$ & 10,12 & 5,96 \\
\hline CT com CF diluído safra de milho ( $\left.\mathrm{R} \$ \mathrm{sc}^{-1}\right)$ & 54,26 & 23,92 \\
\hline $\mathrm{CVt}\left(\mathrm{R} \$ \mathrm{ha}^{-1}\right)$ & $2.339,13$ & $1.616,30$ \\
\hline 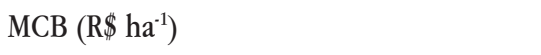 & $1.027,12$ & 363,70 \\
\hline $\mathrm{MCB}(\mathrm{R} \$)$ & $821.694,68$ & $145.480,66$ \\
\hline IMC (\%) & 63,11 & 42,39 \\
\hline IMC Ponderado (\%) & \multicolumn{2}{|c|}{58,40} \\
\hline $\operatorname{MCOE}(\mathrm{R} \$)$ & \multicolumn{2}{|c|}{$413.375,33$} \\
\hline MCOE Sem arrendamento (CO) (R\$) & \multicolumn{2}{|c|}{$810.175,33$} \\
\hline EBITDA $(\mathrm{R} \$)$ & \multicolumn{2}{|c|}{$489.235,50$} \\
\hline Lucro Total Anual (R\$) & \multicolumn{2}{|c|}{$323.475,33$} \\
\hline RT (R\$) & \multicolumn{2}{|c|}{$3.485 .000,00$} \\
\hline
\end{tabular}


(Conclusão)

\begin{tabular}{lcc}
\hline Especificações & Soja & Milho \\
\hline Receita de Equilíbrio (RE) (R\$) & $1.102 .203,28$ \\
Margem de Lucro (ML) (\%) & 9,28 \\
Ponto de Equilíbrio (PE) em há & 626,70 \\
\hline
\end{tabular}

Especificações

CG total anual com juros (R\$)

Investimento total (R\$)

PE (sc ha- - Soja)

Fonte: Elaborado pelo autor com base nas planilhas da EMBRAPA (2014), CONAB (2010), IMEA-MT (2016) e PECEGE/ESALQ (2015).

Ao diluir o custo fixo da safra de verão proporcional à área de inverno, ter-se-ia para a cultura da soja por hectare CVt de $\mathrm{R} \$ 2.339,13$, CFt de $\mathrm{R} \$ 536,40$ e CT de $\mathrm{R} \$ 2.875,53$, que por unidade produzida (saca) representaria um CVt de $\mathrm{R} \$$ 44,13, CFt de $\mathrm{R} \$ 10,12$ e CT de $\mathrm{R} \$ 54,26$. Neste caso, a cultura da soja representaria um lucro de $\mathrm{R} \$ 490,47$ por hectare semeado, permanecendo inalterado o resultado anual (Tabela 7).

Ainda pelo sistema Barter, mas para a cultura do milho, foi verificado por hectare um custo variável médio de $\mathrm{R} \$ 1.616,30$; sem custo fixo e um custo total médio de $\mathrm{R} \$ 1.616,30$ (Tabela 4), representando por unidade produzida respectivamente, $R \$ 17,96, \mathrm{R} \$ 0,00$ e $\mathrm{R} \$ 17,96$, conferindo um lucro de $\mathrm{R} \$ 363,70 \mathrm{ha}^{-1} \mathrm{ano}^{-1}$. Analogamente, ao diluir o custo fixo com a safra de milho, verificou-se um CVt de $\mathrm{R} \$ 17,96$, CFt de $\mathrm{R} \$ 5,96$ e CT de R\$23,92 por saca. Nessa situação, a cultura do milho representaria um prejuízo de $\mathrm{R} \$ 172,80$ por hectare semeado, permanecendo inalterado o resultado anual, ou seja, lucro de $\mathrm{R} \$ 323.256,00$ com margem de lucro de 9,28\% (Tabela 5).

Comparando-se os resultados dos sistemas (normal e Barter), o sistema Barter possibilitou um lucro total anual 38\% superior ao sistema normal (Tabela 5), sendo $84 \%$ maior na cultura da soja e $5 \%$ na cultura do milho, devido a uma pequena redução nos custos variáveis totais e um aumento na receita da soja.

Nas condições da análise, o sistema Barter é mais vantajoso que o sistema normal até um preço de venda da soja de $\mathrm{R} \$ 66,00$ por saca. Neste preço, o Barter 
apresenta lucro de $\mathrm{R} \$ 281,82 \mathrm{ha}^{-1}$ e o sistema normal lucro de $\mathrm{R} \$ 286,91 \mathrm{ha}^{-1}$. Para o milho, a vantagem é até o preço de $\mathrm{R} \$ 22,50$ por saca. Em vista disso, o lucro no sistema Barter seria de $\mathrm{R} \$ 382,02 \mathrm{ha}^{-1}$ e o livre de $\mathrm{R} \$ 387,97 \mathrm{ha}^{-1}$.

Ao compararem o pagamento de insumos da produção da soja no Estado de Mato Grosso, na safra 2014/15, analisando três cenários com o preço da saca de soja por ocasião da colheita: cenário $1, \mathrm{R} \$ 40,00$; cenário $2, \mathrm{R} \$ 50,00 \mathrm{sc}^{-1}$; e cenário $3, \mathrm{R} \$$ 60,00, Kumitake e Mota (2016) verificaram que nos três cenários a operação Barter mostrou-se economicamente viável, com destaque nos dois primeiros que apresentaram rentabilidade de $\mathrm{R} \$ 144,99 \mathrm{ha}^{-1}$ e $\mathrm{R} \$ 383,99 \mathrm{ha}^{-1}$, respectivamente.

\section{CONSIDERAÇÕES FINAIS}

Muitos produtores, independentemente do tamanho da área cultivada, apresentam dificuldades com relação ao planejamento e gestão de suas atividades. A planilha formulada é uma ferramenta ágil, de fácil manuseio, eficiente e que fornece os custos por unidade semeada, ou produzida, em tempo real, possibilitando ao produtor fazer simulações, com as informações do mercado, identificando os riscos e as oportunidades ao longo do processo produtivo, auxiliando na tomada de decisão, respondendo satisfatoriamente aos questionamentos propostos, visto que os resultados não se mostraram distantes dos resultados dos órgãos oficiais.

A planilha formulada não esgota o assunto; novos estudos visando o aperfeiçoamento e inclusão de mais culturas no ano agrícola se fazem necessários.

Pela análise de custos normal, a propriedade mostrou-se viável economicamente, pois apresentou uma margem de lucro positiva. Embora a margem de lucro seja menor que a taxa Selic, há de considerar que esta embute a inflação.

O sistema de troca (Barter), para a soja, mostra-se mais vantajoso do que o sistema tradicional (normal), até um preço de comercialização da produção livre de $\mathrm{R} \$ 66,00$ por saca. A partir desse preço, o Barter passa a ser menos vantajoso. Para o milho, o valor limite é de $\mathrm{R} \$ 22,50$ por saca. Assim, quanto menor o preço, mais vantajoso se torna o Barter. 


\section{REFERÊNCIAS}

APROSOJA. Informe Técnico Aprosoja $\mathbf{n}^{0}$ 143/2017. Disponível em: file://C:/ Users/uizantoniolorenzoni/Downloads/2017-01-11-15-46-52informe-tecnico-143-novos-valores-de-fethab-e-facs.pdf. Acesso em: jan. 2017.

ARAKAWA, H. H. Percepção do produtor agrícola em relação às operações de barter: um estudo da região de Lucas do Rio Verde (MT). 2014. Dissertação (Mestrado em Economia Aplicada) - Escola Superior de Agricultura Luiz de Queiroz, Universidade de São Paulo, Piracicaba, 2014. doi:10.11606/D.11.2014.tde10062014-095530.

BORGES, A. P. M.; MAINARDI, A.; VELASQUEZ, M. D. P. Avaliação do custo de produção de arroz em pequenas propriedades rurais do Rio Grande do Sul: um estudo de caso. Revista em Agronegócio e Meio Ambiente, v. 6, n. 1, p. 99-116, 2013.

BROCH, D. L.; PEDROSO, R. S. Custo de produção da cultura da soja safra 2011/2012. Fundação MS. Disponível em: http://www.fundacaoms.org.br/base/ www/fundacaoms.org.br/media/attachments/24/24/5385dbacc8813316b1159baac903432995f37dbf25894_11-custo-de-producao-da-soja_1016324339.pdf. Acesso em: 14 dez. 2016.

CONAB. Custos de produção agrícola: a metodologia da Conab. Brasília. 60 p. Disponivel em: http://www.conab.gov.br/conabweb/download/safra/custos.pdf. Acesso em: 15 jul. 2016.

CONAB. Custos de produção: Culturas de verão. Disponível em: http://www.conab.gov.br/conteudos.php?a=1554\&t=2. Acesso em: 25 set. 2016 .

CONAB. Evolução dos custos de produção de soja no Brasil. Compêndio de Estudos Conab. v. 2, 24 p. Disponível em: http://www.conab.gov.br/OlalaCMS/ 
uploads/arquivos/16_09_14_15_10_40_compendio_de_estudos_conab_-_volume_2,_2016.pdf. Acesso em: 10 out. 2016.

CONAB. Custos de produção: Culturas da seca. Disponível em: http://www.conab. gov.br/conteudos.php?a=1564\&t=2. Acesso em: 25 set. 2016.

CONAB. Levantamento de safra 2016/17: Grãos. Disponível em: http://www.conab.gov.br/conteudos.php?a=1253\&. Acesso em: 10 fev. 2017.

DELAI, A. P. D.; ARAUJO, J. B. de; REIS, J. G. M. dos; SILVA, L. F. da. Armazenagem e ganhos logísticos: uma análise comparativa para comercialização da soja em Mato Grosso do Sul. Revista em Agronegócio e Meio Ambiente, v. 10, n. 2, p. 395-414, 2017.

EMBRAPA. Avaliação econômica da produção de soja para a safra 2014/15.

Circular Técnica 107. 1. ed. Londrina. 22 p. Disponível em: https://www.embrapa. br/soja/busca-de-publicacoes/-/publicacao/1000876/avaliacao-economica-da-producao-de-soja-para-a-safra-201415. Acesso em: 20 jun. 2016.

FERREIRA, B. G. C.; FREITAS, M. M. L.; MOREIRA, G. C. Custo operacional efetivo de produção de soja em sistema de plantio direto. Revista iPecege, v. 1, n. 1, p. 39-50. 2015.

IMEA. Custo de produção da soja: safra 2016/17. Disponível em: http://www. imea.com.br/upload/publicacoes/arquivos/04102016180808.pdf. Acesso em: 15 out. 2016.

IMEA. Custo de produção do milho: safra 2016/17. Disponível em: http://www. imea.com.br/upload/publicacoes/arquivos/04102016180718.pdf. Acesso em: 15 out. 2016.

KUMITAKE, A.; MOTA, E. P. Análise comparativa do pagamento de insumos da produção da soja no Estado de Mato Grosso. Revista iPecege, v. 2, n. 4, p. 24-41, 2016. 
MARION, J. C.; SANTOS, G. J.; GRATERON, I. R. G.; LEMES, S.; PEREIRA, E.; PROCÓPIO, A. M. Contabilidade e controladoria em agrobusiness. São Paulo: Editora Atlas, 1996.

MARION, J. C.; SANTOS, G. J. Administração de custos na agropecuária. 2. ed. São Paulo: Editora Atlas, 1996.

MARTINES FILHO, J. A importância da análise de gestão na agropecuária: controle de custos e aumento da rentabilidade. Disponível em: http://www.gestiopolis. com/analise-gestao-agropecuaria-controle-custos-aumento-rentabilidade/. Acesso em: 26 jan. 2017.

MAPA. Programa de subvenção ao prêmio do seguro rural - PSR. Relatório estatístico 2016. Disponível em: http://www.agricultura.gov.br/assuntos/riscos-seguro/ seguro-rural/documentos-seguro-rural/ResultadoGeralPSR2016.pdf. Acesso em: 22 fev. 2017.

MIRANDA, P. Contabilidade: fator de desenvolvimento do Agronegócio. Disponível em: http:/www.paginarural.com.br/artigo/2391/contabilidade-fator-de-desenvolvimento-do-agronegocio. Acesso em: 30 abr. 2016.

OLIVEIRA, A. L. R. de; MASCARENHAS, C.; LOPES, B. F. R.; MORINI, C. Aplicação de modelagem matemática para otimização da logística de exportação do milho do estado do Mato Grosso. Revista em Agronegócio e Meio Ambiente, v. 8, n. 3, p. 505-522, 2015.

PACHECO, L. C. Barter pode ser a melhor alternativa para financiar a safra. Disponível em: http://www.canalrural.com.br/noticias/agricultura/barter-pode-ser-melhor-alternativa-para-financiar-safra-62616\# article_selector. Acesso em: $05 \mathrm{dez}$. 2016.

PERINA, R. A. Custo de produção e elaboração de projetos - Estrutura de custos - Metodologia PECEGE/ESALQ. MBA em Agronegócio, turma 2015/17. Cuiabá. 224 p. 2015.

PINHEIRO, A. C. D.; BASSOLI, M. K. Sustentabilidade econômica e ambiental: um 
ideal da sociedade internacional. Scientia Iuris, v. 9, n. 1, p. 109-130, 2005.

ROS, M. Como ter sucesso plantando milho. Disponível em: http://www.pioneersementes.com.br/blog/69/como-ter-sucesso-plantando-milho. Acesso em: 04 mai. 2016.

SEFAZ/MT. Portaria 224/2016, de 22 de dezembro de 2016. Atualização Monetária UPF/MT. Diário Oficial do Estado de Mato Grosso, Cuiabá, 26 dez. 2016. Disponível em: http://app1.sefaz.mt.gov.br/0325677500623408/7C7B6A9347C50F55032569140065EBBF/697301108AD6357A84258096005E7EE4. Acesso em: jan. 2017.

SILVA, M. S. da; MENEZES, T. M. Corredor de escoamento Noroeste: alternativa logística para produtores agrícolas das regiões Centro e Norte do estado do Mato Grosso. Revista em Agronegócio e Meio Ambiente, v. 1, n. 1, p. 37-44, 2008.

SOUZA, R. O.; CREMASCO, C. P.; GABRIEL FILHO, L. R. A. Análise dos valores de frete da soja a granel nos sistemas unimodal e multimodal de transporte. Revista em Agronegócio e Meio Ambiente, v. 9, n. 4, p. 819-837, 2016.

VALERINI, J. P.; KUWAHARA, M. Y. O mercado da soja: Evolução da commodity frente aos mercados internacional e doméstico. Revista Jovens Pesquisadores, v. 4, n. 1 (6), p. 1-20, 2007.

Recebido em: 06/07/2017 